УДК 159.9

DOI 10.23951/2307-6127-2020-1-54-63

\title{
МЕЖЛИЧНОСТНЫЕ ОТНОШЕНИЯ ПОДРОСТКОВ С УМСТВЕННОЙ ОТСТАЛОСТЬЮ, ОСЛОЖНЕННОЙ НАРУШЕНИЕМ ЗРЕНИЯ
}

\author{
Е. В. Гребенникова, И. Л. Шелехов, Е. А. Филимонова \\ Томский государственный педагогический университет, Томск
}

\begin{abstract}
Межличностные отношения являются необходимым условием, определяющим развитие не только отдельных психических процессов, но и личности в целом. Имеется ряд работ, в которых показана деформация межличностных отношений у подростков с разным видом дизонтогенеза, в том числе и при умственной отсталости. Представлены результаты изучения межличностных отношений подростков, имеющих умственную отсталость, осложненную нарушением зрения. Результаты проведенного исследования позволили констатировать наличие как общих, так и специфических особенностей межличностных отношений у подростков с умственной отсталостью, осложненной нарушением зрения, и у их сверстников с неосложненной умственной отсталостью. В обследуемых группах только треть подростков рассматривают отца и мать как родительскую чету, при этом наблюдается высокая значимость взаимоотношений с матерью и отказ от общения с отцом. Для подростков обеих групп характерны: слабая включенность во взаимодействие со сверстниками; наличие чувственно дефицитного или чувственно чрезмерного типа взаимодействия с преобладанием чувственно дефицитного типа; нерешительность в принятии решений, стремление переложить ответственность на других; отсутствие тенденции к доминированию; частые конфликты со сверстниками и неспособность их конструктивно разрешить. Кроме того, подростки обследуемых групп часто демонстрируют реакции на фрустрацию активно-агрессивного или пассивно-страдательного типа, причем у подростков с неосложненной умственной отсталостью доминируют реакции активно-агрессивного типа, а у подростков с умственной отсталостью, осложненной нарушением зрения, - реакции пассивно-страдательного типа. Примечательно, что подростки с умственной отсталостью, осложненной нарушением зрения, склонны к изоляции от сверстников, проявляют бо́льшую привязанность к дому и своей семье.
\end{abstract}

Ключевые слова: межличностные отночения, подростковый возраст, умственная отсталость, нарушение зрения.

В настоящее время отечественными и зарубежными учеными выполнено большое количество психологических исследований, посвященных различным аспектам межличностных отношений. Так, в отечественной психологии

- Б. Г. Ананьев [1] и В. Н. Мясищев [2], говоря о природе межличностного взаимодействия, выделяли три составляющие: познание людьми друг друга, отношение друг к другу в виде эмоционального отклика и обращение человека с человеком в процессе общения;

- Л. Анерт и соавт. [3], А. П. Оконешникова [4], Е. Н. Резникова [5], С. Д. Гуриева [6], занимаясь изучением межличностных отношений на межэтническом уровне, отметили влияние межнациональных различий на характер межличностных отношений;

- А. А. Реан [7], Я. Л. Коломинский [8], С. Кон [9], А. В. Мудрик [10], В. В. Обозов [11] подчеркивали роль и место межличностных отношений в образовательном пространстве; 
- Т. Е. Аргентова [12], Г. А. Берулава [13], Е. А. Климов [14], В. Н. Куницына [15], В. В. Латынов [16], В. С. Мерлин [17] исследовали стилевые особенности межличностного взаимодействия;

- В. П. Левкович [18], В. А. Смехов [19], А. Р. Шавалеева [20], Э. Г. Эйдмиллер и В. В. Юстицкис [21] проводили анализ межличностных семейных отношений;

- Д. И. Джидарьян [22], К. Е. Изард [23], В. А. Лабунская [24], Ю. А. Менджерицкая [25], А. И. Крупное и соавт. [26] изучали влияние чувств и эмоций на характер взаимоотношений между людьми.

Имеется немало исследований, касающихся межличностных отношений детей и подростков с дизонтогенетическим развитием, в том числе с умственной отсталостью [27-29]. Известно, что при умственной отсталости наблюдаются: задержка и неустойчивость в развитии межличностных отношений; затруднение развития коммуникативных связей; большое количество мелких микрогрупп; частая смена неофициальных лидеров, при этом часто лидеры выделяются по случайному признаку; большая численность детей в крайних статусных категориях, особенно в категории «изолированных»; нестабильность и нестойкость проявления эмпатии и сочувствия; фрагментарность социального опыта [30-33]. Однако следует отметить, что исследований, в которых изучалась специфика межличностных отношений подростков, имеющих умственную отсталость, осложненную нарушением функций анализаторов, достаточно мало, хотя количество таких детей среди обучающихся специальных школ с каждым годом увеличивается. Безусловно, исследования, направленные на изучение межличностных отношений у данной категории подростков, имеют важное значение, прежде всего для организации эффективного взаимодействия между участниками образовательного процесса.

Нами было проведено исследование, целью которого являлось изучение межличностных отношений подростков с умственной отсталостью, осложненной нарушением зрения.

Исследование проводилось в период с 2014 по 2019 г. на базе трех образовательных учреждений г. Томска: МБОУ ООШ № 39, МБОУ ООШИ № 22, ОГКОУ «Школа-интернат для обучающихся с нарушениями зрения». В исследовании приняли участие 60 подростков с легкой умственной отсталостью 13-16 лет, которые составили две равнозначные по численности группы: 1-я группа - подростки с неосложненной умственной отсталостью; 2-я группа - подростки с умственной отсталостью, осложненной нарушением зрения (Н49-Н54 по МКБ-10).

Для изучения межличностных отношений подростков использовали анкету «Мое окружение»; методику Р. Жиля «Фильм-тест», адаптированную И. Н. Гильяшевой и Н. Д. Игнатьевой; опросник межличностных отношений (OMO) В. Шутца, «Оценка отношений с классом».

Все подростки, участвовавшие в обследовании, охотно согласились ответить на вопросы анкеты. Во время анкетирования обучающиеся вели себя адекватно. В случае возникновения вопросов обучающийся мог получить комментарий со стороны психолога.

Из ответов на вопрос «С кем ты живешь?» выяснили, что большая часть подростков 1-й $(80 \%)$ и 2-й (60 \%) группы проживают в полных семьях. Воспитанием подростков из неполных семей занимались матери, которым часто помогали дедушки и бабушки.

На вопрос «Тебе нравится проводить время дома? Хочешь поскорее пойти из школы домой?» 60 \% подростков 1-й группы ответили утвердительно, 33 \% подростков сказали о том, что им не хочется идти домой, если в семье конфликтная ситуация, и лишь 7 \% подростков были категоричны - они не хотят возвращаться из школы домой. Иная ситуация была отмечена во 2-й группе подростков. В указанной группе 73 \% подростков после 
школы как можно быстрее хотят вернуться домой; 27 \% подростков только иногда не хотят идти домой.

Подростки 1-й и 2-й группы, проживающие в условиях интерната, в своих ответах отмечали нежелание возвращаться домой. В качестве причин называли плохие бытовые условия, отсутствие внимания со стороны членов семьи и частые конфликты.

На вопрос «Твои родители часто разговаривают с тобой о твоих делах?» ответы подростков обеих групп распределились однотипно: 20 \% подростков ответили положительно, $60 \%$ отметили, что родители редко интересуются их делами, $20 \%$ указали, что родители безразличны к их деятельности. Большую часть подростков, отметивших безразличие родителей к их деятельности, составили дети, проживающие в условиях интерната.

На вопрос «Тебе спокойно дома? Не страшно?» больше половины подростков 1-й (60 \%) и 2-й (67 \%) группы ответили, что им дома достаточно комфортно.

На вопрос «Родители часто с тобой играют? Гуляют? Читают тебе книжки?» 80 \% подростков обеих обследуемых групп ответили, что родители взаимодействуют с ними редко. При этом инициатором общения выступает подросток. К сожалению, 20 \% подростков отметили отсутствие взаимодействия с родителями.

Из ответов на вопрос «Если тебя кто-нибудь обидел или ты просто расстроился, ты сразу расскажешь обо всем маме, папе или другу? Никому не расскажешь?» видно, что из 1-й группы 47 \% подростков не расскажут никому, $33 \%$ - матери, $20 \%$ - другу. Во 2-й группе $47 \%$ подростков расскажут матери, $33 \%$ подростков никому не расскажут и $20 \%$ подростков расскажут о своей проблеме другу. Важно отметить, что подростки 1-й и 2-й группы, проживающие в условиях интерната, о своей проблеме предпочитают никому не говорить.

На вопрос «Если ты хочешь, но затрудняешься что-либо сказать, как поступят твои родители?» 40 \% подростков 1-й группы и $33 \%$ подростков 2-й группы ответили, что их терпеливо выслушают и помогут справиться с возникшей проблемой. Больше половины подростков 1-й $(60 \%)$ и 2-й (67 \%) группы сообщили о том, что в данной ситуации их не дослушают и отправят к другому родителю. Полученные результаты отражают нетерпимое отношение родителей к своим детям, что, безусловно, негативно сказывается на детско-родительских отношениях.

На вопрос «Много ли у тебя друзей?» подростки 1-й группы ответили следующим образом: больше трех друзей - $27 \%$, только один друг - $53 \%$, не имею друзей - $20 \%$. Во 2-й группе больше трех друзей указали $13 \%$ подростков, об одном друге упомянули $60 \%$ и 27 \% считают, что у них нет друзей. Из ответов видно, что 20-27 \% подростков обследуемых групп не имеют друзей, что негативно сказывается на их социально-психологическом развитии.

На вопрос «Доверили бы свою тайну другу и обратились бы к нему за помощью в трудной ситуации?» только 20 \% подростков 1-й и 2-й группы ответили утвердительно.

На вопрос «За что ты любишь друзей?» в обеих группах чаще всего звучали такие ответы, как: он хороший, добрый, веселый.

На вопрос «Часто ли вы с друзьями ссоритесь?» больше половины подростков 1-й $(80 \%)$ и 2-й $(67 \%)$ группы ответили положительно. При этом в большинстве случаев конфликты разрешаются с помощью воспитателя или педагога. В ситуации, когда подросток пытается самостоятельно выйти из конфликтной ситуации, он использует неконструктивные копинг-стратегии.

На основании результатов анкетирования можно сказать, что подростки обеих групп: 1) имеют родителей, которые уделяют им мало времени и часто безразличны к их пробле- 
мам; 2) выстраивают более доверительные отношения с матерью; 3) испытывают трудности в общении со сверстниками и при возникновении конфликтных ситуаций не способны их конструктивно разрешить.

В то же время анкетирование показало, что подростки 2-й группы демонстрируют большую привязанность к дому и своей семье, в то время как подростки 1-й группы имеют больше друзей.

Используя методику Р. Жиля, выявили, что у 60 \% подростков 1-й группы показатель по шкале «Конфликтность/агрессивность» высокий, у 40 \% подростков - низкий. Во 2-й группе отмечалась противоположная ситуация - 40 \% подростков имели высокий показатель по данной шкале, а 60 \% подростков - низкий.

По шкале «Реакция на фрустрацию» в 1-й группе доминирующими оказались реакции активно-агрессивного типа (53 \%): крик, высмеивание, протест, пойти куда-то вопреки запрету, злость, драки. Во 2-й группе чаще регистрировались реакции пассивно-страдательного типа (60 \%): плач, обида, жалобы. Интересно, что реакции нейтрального типа были характерны для одинакового количества подростков из двух обследуемых групп (13\%).

По шкале «Стремление к уединению, отгороженность» среди подростков 1-й группы не выявлена тенденция к изоляции от сверстников, в то время как во 2-й группе у $20 \%$ подростков такая тенденция обнаружена. Важно заметить, что у подростков как 1-й, так и 2-й группы наблюдается слабая включенность во взаимодействие со сверстниками, о чем свидетельствуют низкие показатели по шкале «Стремление к общению в больших группах детей». Кроме того, у большинства подростков обследованных групп (80\%) отсутствует тенденция к доминированию (шкала «Доминирование»).

Результаты исследования, полученные по шкалам «Отношение к матери», «Отношение к отцу», «Отношение к матери и отцу как к родительской чете», позволили определить характер отношений в семье. У $40 \%$ подростков из 1-й группы и 53 \% подростков из 2-й группы был отмечен низкий контакт с отцом на фоне предпочтения матери (подростки, в воспитании которых отцы не принимали участия, по соответствующей шкале не отметили значимость отношений с родителем). У подростков 1-й и 2-й группы, проживающих в интернате, стремление к общению с матерью выражено сильнее, чем у их подростков, проживающих в семье.

По шкале ««Отношение к матери и отцу как к родительской чете» разницы в средних показателях обеих групп подростков не отмечается. Выявлено, что только 33 \% подростков воспринимают мать и отца как родительскую чету. Полученные результаты отражают объективную семейную ситуацию: подростки, воспитывающиеся в полных и благополучных семьях, как правило, воспринимают отца и мать как родительскую чету, а подростки, родители которых не проживают вместе или находятся в конфликтных отношениях, не характеризуют их как пару.

Исходя из результатов, полученных по шкалам «Отношение к бабушке, дедушке и другим родственникам», «Отношение к братьям и сестрам», можно сказать о хорошем отношении большей части подростков обследуемых групп к бабушкам и дедушкам, а также сестрам и братьям. Хотя среди подростков имелись и такие, которые демонстрировали нейтральное отношение к данной категории родственников. В тех случаях, когда воспитанием подростков занимались преимущественно бабушки и дедушки, они демонстрируют высокую значимость отношений с ними.

Потребность во взаимодействии со сверстниками выражена у $27 \%$ подростков из 1-й группы и $24 \%$ подростков из 2-й группы. Примечательно, что для $33 \%$ подростков 1 -й группы и 40 \% подростков 2-й группы значимыми являются отношения с педагогом. 
Результаты, полученные по методике Р. Жиля, позволяют сделать следующие выводы:

1. Среди подростков 1-й и 2-й группы имеется достаточно большой процент тех, кто имеет низкий показатель контактов с отцом на фоне предпочтения матери. Кроме того, только треть подростков каждой группы рассматривает отца и мать как родительскую чету.

2. У большинства подростков обследуемых групп отмечается слабая включенность во взаимодействие со сверстниками и отсутствие тенденции к доминированию.

3. Подростки обследуемых групп чаще демонстрируют реакции активно-агрессивного или пассивно-страдательного типа. Причем у подростков 1-й группы доминируют реакции активно-агрессивного типа, а у подростков 2-й группы - пассивно-страдательного типа.

С помощью опросника В. Шутца у подростков обследуемых групп определяли особенности межличностного поведения, исходя из трех потребностей - включения, контроля, аффекта.

В области включения у подростков обеих групп определены четыре типа поведения. Социально дефициентный тип имели 40 \% подростков 1-й группы и 50 \% подростков 2-й группы. Социально чрезмерный и социально уравновешенный типы поведения встречались в равных процентных соотношениях - по 27 \% в 1-й группе и по 20 \% во 2-й группе. С патологическим типом межличностных отношений в 1-й группе оказалось 6 \% подростков, а во 2-й группе - 10 \%. Таким образом, для большей части обследованных характерно социально нежелательное поведение с преобладанием социально дефициентного типа межличностного поведения, при котором у подростков отмечаются невысокий уровень включения, необщительность, избегание больших компаний сверстников.

В области контроля среди подростков обеих групп выделены четыре типа межличностных отношений. Распределение типов межличностных отношений в области контроля было следующим: абдикраты - 40 \% в 1-й группе и 50 \% во 2-й группе, автократы и демократы - по 27 \% в 1-й группе и по $20 \%$ во 2-й группе, патология - 6 \% в 1-й группе и $10 \%$ во2-й группе. Из представленных результатов видно, что в обследуемых группах чаще встречаются подростки-абдикраты, для которых характерно подчинение, нерешительность в принятии решений, стремление переложить ответственность на других.

В области аффекта как в 1-й, так и во 2-й группе выявили три типа межличностных отношений: чувственно дефицитный, чувственно чрезмерный, чувственно уравновешенный. При этом среди подростков обследуемых групп чаще встречался чувственно дефицитный тип (40 \% в 1-й группе и 50 \% во 2-й группе), при котором подростки обладают слабым чувством эмоциональной привязанности, стремятся избегать близких личных отношений с окружающими. Важно отметить, что достаточно большой процент подростков (33 \%) обеих групп имели чувственно чрезмерный тип отношений.

Представленные результаты свидетельствуют о том, что больше половины обследуемых подростков в области аффекта обладают социально неадекватными типами межличностных отношений - чувственно дефицитным или чувственно чрезмерным.

Используя методику «Оценка отношений подростка с классом», обнаружили, что у подростков обследуемых групп чаще всего встречается индивидуалистический тип восприятия: в 1-й группе - у 47 \%, во 2-й группе - у 60 \%. Подростки с таким типом воспринимают группу как помеху своей деятельности или относятся к ней нейтрально. Группа не представляет ценности для личности подростка. Ребенок уклоняется от совместных форм деятельности, предпочитая индивидуальную работу, ограничен в контактах.

Помимо индивидуалистического типа восприятия, у подростков обеих групп встречается также прагматический тип. Такой тип восприятия характерен для 33 \% подростков 1-й группы и 20 \% подростков 2-й группы. Дети с таким типом воспринимают группу как 
средство, способствующее достижению тех или иных индивидуальных целей. При этом группа воспринимается и оценивается с точки зрения ее полезности для самого подростка. Отдается предпочтение более компетентным членам группы, способным оказать помощь, взять на себя решение сложной проблемы или послужить источником необходимой информации.

Только 20 \% подростков из обследуемых групп воспринимают группу как самостоятельную ценность. На первый план для них выступают проблемы группы и отдельных ее членов, наблюдается заинтересованность как в успехах каждого члена группы, так и группы в целом, стремление внести свой вклад в групповую деятельность, оказать помощь нуждающимся в этом одноклассникам. Проявляется потребность в коллективных формах работы. Этот тип восприятия индивидом своей группы назван коллективистическим.

Таким образом, у большей части подростков обследуемых групп отмечается направленность на себя и предпочтение индивидуалистического типа восприятия группы. Группа не представляет собой самостоятельной ценности для личности подростка.

Обобщая результаты эмпирического исследования, можно сказать, что межличностные отношения подростков с умственной отсталостью, осложненной нарушением зрения, во многом повторяют таковые у подростков с неосложненной формой умственной отсталости, однако имеются и специфические особенности, которые важно учитывать при планировании коррекционно-развивающей работы по формированию оптимальных межличностных отношений.

\section{Список литературы}

1. Ананьев Б. Г. Человек как предмет познания. СПб.: Питер, 2001. 288 с.

2. Мясищев В. Н. Психология отношений / под ред. А. А. Бодалева. М.: МПСИ, 2003. 104 с.

3. Анерт Л., Майшнер Т., Шмидт А., Доскин В. А. Кросс-культурное исследование взаимодействия с детьми русских и немецких матерей // Вопросы психологии. 1994. № 5. С. 20-30.

4. Оконешникова А. П. Межэтническое восприятие и понимание людьми друг друга. Пермь: Звезда, 1999. 406 с.

5. Резников Е. Н. Психология этнического общения. М.: Ин-т психологии РАН, 2007. 160 с.

6. Гуриева С. Д. Методологические и теоретические аспекты изучения межэтнических отношений. СПб.: Изд-во СПбГУ, 2010. $180 \mathrm{C}$.

7. Реан А. А., Коломинский Я. Л. Социальная педагогическая психология. СПб.: Питер, 2000. 416 c.

8. Коломинский Я. Л. Психология детского коллектива: система личных взаимоотношений. Минск: Народная асвета, 1984. 239 c.

9. Кон И. С. Психология старшеклассника: пособие для учителей. М.: Просвещение, 1980. 191 с.

10. Мудрик А. В. Общение как фактор воспитания школьников. М.: Педагогика, 1984. 112 с.

11. Обозов В. В. Динамика межличностных отношений студентов и ее связь с экстраверсией и нейротизмом // Человек и общество. 1973. Вып. 13. С. 149-154.

12. Аргентова Т. Е. Стиль общения как фрактор эффрективности совместной деятельности // Психологический журнал. 1984. № 6. С. 130-133.

13. Берулава Г. А. Стиль индивидуальности: теория и практика: учебное пособие. М.: Педагогическое общество России, 2001. $236 \mathrm{c}$.

14. Климов Е. А. Индивидуальный стиль деятельности в зависимости от типологических свойств нервной системы. Казань: КГУ, 1969. 278 с.

15. Куницына В. Н. Стиль общения и его формирование. Л.: Знание, 1985. 20 с.

16. Латынов В. В. Стили речевого коммуникативного поведения: структуры и детерминанты // Психологический журнал. 1995. № 6. С. 90-100.

17. Мерлин В. С. Индивидуальный стиль общения // Психологический журнал. 1982. № 4. С. 26-36. 
18. Левкович В. П. Особенности супружеских взаимоотношений в разнонациональных семьях // Психологический журнал. 1990. № 1. С. $25-36$.

19. Смехов В. А. Опыт психологической диагностики и коррекции конфликтного общения в семье // Вопросы психологии. 1985. № 4. C. 83-92.

20. Шавалеева А. Р., Айдаров В. Особенности общения и межличностных отношений супругов в современной молодой семье // Научное обозрение. Педагогические науки. 2017. № 6-1. С. 143-145.

21. Эйдемиллер Э. Г., Юстицкис В. В. Психология и психотерапия семьи. СПб.: Питер, 1999. 656 с.

22. Джидарьян И. А. Психология счастья и оптимизма. М.: Ин-т психологии РАН, 2013. 268 с.

23. Изард К. Психология эмоций. СПб.: Питер, 2000. 460 c.

24. Лабунская В. А., Менджерицкая Ю. А., Бреус Е. Д. Психология затрудненного общения: Теория. Методы. Диагностика. Коррекция. М.: Академия, 2001. $288 \mathrm{c.}$

25. Менджерицкая Ю. А. Особенности эмпатии субъектов затрудненного общения // Практическая психология. 1999. № 4. C. 54-64.

26. Крупнов А. И., Ольшанникова А. Е., Домодедов В. А. Соотношение показателей эмоциональности и динамических характеристик общения // Вопросы психофизиологии активности и саморегуляции личности. Свердловск, 1979. C. $17-25$.

27. Вийтар Э. А. Исследование межличностных отношений и интерперсональной перцепции слабослышащих школьников // Дефектология. 1981. № 4. С. 30-35.

28. Гребенникова Е. В., Шелехов И. Л., Лялина И. И. Межличностное общение как маркер эффеккивной социализации подростков с задержкой психического развития // Научно-педагогическое обозрение (Pedagogical Review). 2016. Вып. 1 (11). С. 26-30.

29. Гребенникова Е. В., Шелехов И. Л., Шелкунова А. Ф. Социально-психологические особенности детей старшего дошкольного возраста с нарушениями речи // Научно-педагогическое обозрение (Pedagogical Review). 2018. Bып. 4 (22). C. 18-26. DOI: 10.23951/2307-6127-2018-4-18-26.

30. Шипицына Л. М. «Необучаемый» ребенок в семье и обществе. Социализация детей с нарушением интеллекта. СПб.: Речь, 2005. 477 с.

31. Гордиенко Е. А. Некоторые психолого-педагогические аспекты взаимоотношений умственно отсталых учащихся в коллективе // Дефектология. 1981. № 5. С. 14-20.

32. Никандрова Т. С. Межличностные отношения подростков с интеллектуальной недостаточностью и их развитие // Дети с проблемами в развитии. 2004. № 3. С. 15-17.

33. Печерский В. Г., Печерский А. В. Коммуникативная активность подростков с интеллектуальным недоразвитием в контексте проблем продуктивного личностного взаимодействия // Дефектология. 2006. № 3. С. 46-52.

Гребенникова Елена Владимировна, кандидат биологических наук, доцент, Томский государственный педагогический университет (ул. Киевская, 60, Томск, Россия, 63406). E-mail: grebennikova971@mail.ru

Шелехов Игорь Львович, кандидат психологических наук, доцент, член-корреспондент Международной академии психологических наук, доцент кафедры, Томский государственный педагогический университет (ул. Киевская, 60, Томск, Россия, 63406).

E-mail: brief@sibmail.com

ORCID iD: 0000-0001-7672-1064

SPIN-код: 8638-6249

Филимонова Елена Анатольевна, старший преподаватель, Томский государственный педагогический университет (ул. Киевская, 60, Томск, Россия, 63406).

E-mail: filimonova64@list.ru 


\title{
INTERPERSONAL RELATIONS OF ADOLESCENTS WITH MENTAL RETARDATION, COMPLICATED BY VISUAL IMPAIRMENT
}

\author{
E. V. Grebennikova, I. L. Shelekhov, E. A. Filimonova
}

\section{Tomsk State Pedagogical University, Tomsk, Russian Federation}

Interpersonal relations are a prerequisite that determines the development of not only individual mental processes, but also the personality as a whole. There are a number of works that show the deformation of interpersonal relationships in adolescents with different types of dysontogenesis, including with mental retardation. This article presents the results of a study of the interpersonal relationships of adolescents with mental retardation complicated by visual impairment. The results of the study made it possible to ascertain the presence of both general and specific features of interpersonal relationships in adolescents with mental retardation complicated by visual impairment, and their peers with uncomplicated mental retardation. In the examined groups, only a third of adolescents consider the father and mother as a parental couple, while there is a high significance of the relationship with the mother and refusal to communicate with the father. For adolescents of both groups are characteristic: weak involvement in interaction with peers; the presence of a sensually deficient or sensually excessive type of interaction with a predominance of the sensually deficient type; indecision in decision making, the desire to shift responsibility to others; lack of a tendency to domination; frequent conflicts with peers and the inability to constructively resolve them. In addition, adolescents of the studied groups often show reactions to frustration of the activeaggressive or passive-suffering type, and in adolescents with uncomplicated mental retardation, the reactions of the active-aggressive type dominate, and in adolescents with mental retardation complicated by visual impairment, the reactions of passive-passive type. It is noteworthy that adolescents with mental retardation, complicated by visual impairment, are prone to isolation from their peers, show greater attachment to home and their family.

Keywords: interpersonal relationships, adolescence, mental retardation, visual impairment.

\section{References}

1. Anan'yev B. G. Chelovek kak predmet poznaniya [Man as a subject of knowledge]. Saint Petersburg, Piter Publ., 2001. 288 p. (in Russian).

2. Myasishchev V. N. Psikhologiya otnosheniy. Pod red. A. A. Bodaleva [Psychology of relations. Ed. A. A. Bodalev]. Moscow, MPSI Publ., 2003. 104 p. (in Russian).

3. Anert L., Mayshner T., Shmidt A., Doskin V. A. Kross-kul'turnoye issledovaniye vzaimodeystviya s det'mi russkikh i nemetskikh materey [Cross-cultural study of interaction with children of Russian and German mothers]. Voprosy psikhologii - Voprosy Psychologii, 1994, no. 5, pp. 20-30 (in Russian).

4. Okoneshnikova A. P. Mezhetnicheskoye vospriyatiye i ponimaniye lyud'mi drug druga [Interethnic perception and understanding by people of each other]. Perm', Zvezda Publ., 1999. 406 p. (in Russian).

5. Reznikov Ye. N. Psikhologiya etnicheskogo obshcheniya [Psychology of ethnic communication]. Moscow, Institute of Psychology RAS Publ., 2007. 160 p. (in Russian).

6. Guriyeva S. D. Metodologicheskiye i teoreticheskiye aspekty izucheniya mezhetnicheskikh otnosheniy [Methodological and theoretical aspects of the study of interethnic relations]. Saint Petersburg, St. Petersburg State University Publ., 2010. 180 p. (in Russian).

7. Rean A. A., Kolominskiy Ya. L. Sotsial'naya pedagogicheskaya psikhologiya [Social pedagogical psychology]. Saint Petersburg, Piter Publ., 2000. 416 p. (in Russian).

8. Kolominskiy Ya. L. Psikhologiya detskogo kollektiva: sistema lichnykh vzaimootnosheniy [Psychology of the children's team: system of personal relationships]. Minsk, Narodnaya asveta Publ., 1984. 239 p. (in Russian). 
9. Kon I. S. Psikhologiya starsheklassnika: posobiye dlya uchiteley [Psychology of a high school student: a manual for teachers]. Moscow, Prosvyashcheniye Publ., 1980. 191 p. (in Russian).

10. Mudrik A. V. Obshcheniye kak faktor vospitaniya shkol'nikov [Communication as a factor in the education of schoolchildren]. Moscow, Pedagogika Publ., 1984. 112 p. (in Russian).

11. Obozov V. V. Dinamika mezhlichnostnykh otnosheniy studentov i yeye svyaz's ekstraversiyey i neyrotizmom [Dynamics of interpersonal relations of students and its relationship with extraversion and neuroticism]. Chelovek i obshchestvo, 1973, no. 13, pp. 149-154 (in Russian).

12. Argentova T. Ye. Stil' obshcheniya kak faktor effektivnosti sovmestnoy deyatel'nosti [Communication style as a factor in the effectiveness of joint activities]. Psikhologicheskiy zhurnal - Psychological Journal, 1984, no. 6, pp. 130-133 (in Russian).

13. Berulava G. A. Stil' individual'nosti: teoriya i praktika: uchebnoye posobiye [Style of individuality: theory and practice: a training manual]. Moscow, Pedagogicheskoye obshchestvo Rossii Publ., 2001. 236 p. (in Russian).

14. Klimov Ye. A. Individual'nyy stil' deyatel'nosti v zavisimosti ot tipologicheskikh svoystv nervnoy sistemy [Individual style of activity depending on the typological properties of the nervous system]. Kazan', KSU Publ., 1969. 278 p. (in Russian).

15. Kunitsyna V. N. Stil' obshcheniya i yego formirovaniye [Communication style and its formation]. Leningrad, Znaniye Publ., 1985. 20 p. (in Russian).

16. Latynov V. V. Stili rechevogo kommunikativnogo povedeniya: struktury i determinanty [Styles of speech communicative behavior: structures and determinants]. Psikhologicheskiy zhurnal - Psychological Journal, 1995, no. 6, pp. 90-100 (in Russian).

17. Merlin V. S. Individual'nyy stil' obshcheniya [Individual communication style]. Psikhologicheskiy zhurnal - Psychological Journal, 1982, no. 4, pp. $26-36$ (in Russian).

18. Levkovich V. P. Osobennosti supruzheskikh vzaimootnosheniy v raznonatsional'nykh sem'yakh [Features of marital relationships in multinational families]. Psikhologicheskiy zhurnal - Psychological Journal, 1990, no. 1, pp. $25-36$ (in Russian).

19. Smekhov V. A. Opyt psikhologicheskoy diagnostiki i korrektsii konfliktnogo obshcheniya v sem'ye [Experience in psychological diagnosis and correction of conflict communication in the family]. Voprosy psikhologii - Voprosy Psychologii, 1985, no. 4, pp. 83-92 (in Russian).

20. Shavaleyeva A. R., Aydarov V. Osobennosti obshcheniya i mezhlichnostnykh otnosheniy suprugov v sovremennoy molodoy sem'ye [Features of communication and interpersonal relations of the married couples are in modern young family]. Nauchnoye obozreniye. Pedagogicheskiye nauki - Science Review. Pedagogical Sciences, 2017, no. 6-1, pp. 143-145 (in Russian).

21. Eydemiller E. G., Yustitskis V. V. Psikhologiya i psikhoterapiya sem'i [Psychology and psychotherapy of the family]. Saint Petersburg, Piter Publ., 1999. 656 p. (in Russian).

22. Dzhidar'yan I. A. Psikhologiya schast'ya i optimizma [Psychology of happiness and optimism]. Moscow, Institute of Psychology of the Russian Academy of Sciences Publ., 2013. 268 p. (in Russian).

23. Izard K. Psikhologiya emotsiy [Psychology of emotions]. Saint Petersburg, Piter Publ., 2000. 460 p. (in Russian).

24. Labunskaya V. A., Mendzheritskaya Yu. A., Breus Ye. D. Psikhologiya zatrudnennogo obshcheniya: Teoriya. Metody. Diagnostika. Korrektsiya [Psychology of difficulty communication: Theory. Methods Diagnostics. Correction]. Moscow, Akademiya Publ., 2001. 288 p. (in Russian).

25. Mendzheritskaya Yu. A. Osobennosti empatii sub"yektov zatrudnennogo obshcheniya [Features of empathy of subjects of difficult communication]. Prakticheskaya psikhologiya, 1999, no. 4, pp. 54-64 (in Russian).

26. Krupnov A. I., Ol'shannikova A. Ye., Domodedov V. A. Sootnosheniye pokazateley emotsional'nosti i dinamicheskikh kharakteristik obshcheniya [Correlation of indicators of emotionality and dynamic characteristics of communication]. Voprosy psikhofiziologii aktivnosti i samoregulyatsii lichnosti [Questions of the psychophysiology of activity and self-regulation of personality]. Sverdlovsk, 1979. Pp. 17-25 (in Russian).

27. Viytar E. A. Issledovaniye mezhlichnostnykh otnosheniy i interpersonal'noy pertseptsii slaboslyshashchikh shkol'nikov [The study of interpersonal relationships and interpersonal perception of hearing impaired students]. Defektologiya - Defectology, 1981, no. 4, pp. 30-35 (in Russian).

28. Grebennikova E. V., Shelekhov I. L., Lyalina I. I. Mezhlichnostnoye obshcheniye kak marker effektivnoy sotsializatsii podrostkov s zaderzhkoy psikhicheskogo razvitiya [Interpersonal communication as a marker of effective socialization of adolescents with mental retardation]. Nauchno-pedagogicheskoye obozreniye - Pedagogical Review, 2016, vol. 1 (11), pp. $26-30$ (in Russian).

29. Grebennikova Ye. V., Shelekhov I. L., ShelkunovaA. F. Sotsial'no-psikhologicheskiye osobennosti detey starshego doshkol'nogo vozrasta s narusheniyami rechi [Social and psychological characteristics of senior preschoolers with speech disorders]. Nauchno-pedagogicheskoye obozreniye - Pedagogical Review, 2018, vol. 4 (22), pp. 18-26 (in Russian). DOl: 10.23951/23076127-2018-4-18-26. 
30. Shipitsyna L. M. "Neobuchayemyy" rebenok v sem'ye i obshchestve. Sotsializatsiya detey s narusheniyem intellekta ["Uneducable" child in the family and society. Socialization of children with intellectual disabilities]. Saint Petersburg, Rech' Publ., 2005. 447 p. (in Russian).

31. Gordiyenko Ye. A. Nekotoryye psikhologo-pedagogicheskiye aspekty vzaimootnosheniy umstvenno otstalykh uchashchikhsya $\mathrm{v}$ kollektive [Some psychological and pedagogical aspects of the relationship of mentally retarded students in the team]. Defektologiya - Defectology, 1981, no. 5, pp. 14-20 (in Russian).

32. Nikandrova T. S. Mezhlichnostnyye otnosheniya podrostkov s intellektual'noy nedostatochnost'yu i ikh razvitiye [Interpersonal relations of adolescents with intellectual disability and their development]. Deti s problemami v razvitii, 2004, no. 3, pp. 15-17 (in Russian).

33. Pecherskiy V. G., Pecherskiy A. V. Kommunikativnaya aktivnost' podrostkov s intellektual'nym nedorazvitiyem v kontekste problem produktivnogo lichnostnogo vzaimodeystviya [Communicative activity of adolescents with intellectual underdevelopment in the context of problems of productive personal interaction]. Defektologiya - Defectology, 2006, no. 3, pp. 46-52 (in Russian).

Grebennikova E. V., Tomsk State Pedagogical University (ul. Kiyevskaya, 60, Tomsk, Russian Federation, 634061).E-mail: grebennikova971@mail.ru

Shelekhov I. L., Tomsk State Pedagogical University (ul. Kiyevskaya, 60, Tomsk, Russian Federation, 634061). E-mail: brief@sibmail.com

ORCID iD: 0000-0001-7672-1064

SPIN: 8638-6249

Filimonova E. A., Tomsk State Pedagogical University (ul. Kiyevskaya, 60, Tomsk, Russian Federation, 634061). E-mail: filimonova64@list.ru 